\title{
Evaluation of Vascular Endothelial Growth Factor and Its Receptors in Human Neointima
}

\author{
Marta Bruczko ${ }^{a}$ Małgorzata Wolańska ${ }^{a}$ Andrzej Małkowski ${ }^{a}$ \\ Krzysztof Sobolewski $^{\mathrm{a}}$ Radosław Kowalewski $^{\mathrm{b}}$ \\ Departments of a Medical Biochemistry and ${ }^{b}$ Vascular Surgery and Transplantology, Medical University of \\ Białystok, Białystok, Poland
}

\section{Key Words}

Neointima - Vascular anastomoses - Vascular endothelial growth factor - Vascular endothelial growth factor receptor V Vascular smooth muscle cells

\begin{abstract}
Objective: The potential contribution of vascular endothelial growth factor (VEGF) in neointima development has been evaluated in numerous animal studies. However, its role remains controversial. Moreover, little is known about neointima formation in humans. In this study we assessed the expression of VEGF-A and its receptors in the human neointima formed within vascular anastomosis. Methods: The studied material comprised neointima samples harvested during secondary vascular operations from patients with chronic limb ischemia after aorto-/iliofemoral bypass grafting who developed vascular graft occlusion at 6-18 months after the initial surgical treatment. The control material consisted of segments of femoral arteries without visible macroscopic lesions collected from organ donors. The expression and content of VEGF-A, VEGFR- 1 and VEGFR- 2 were analyzed with PCR and ELISA methods, respectively. Results: We observed a significantly increased expression of VEGF-A and VEGFR-2 mRNA in neointima compared to the normal aor-
\end{abstract}

\section{KARGER}

E-Mail karger@karger.com

www.karger.com/pat ta. A significantly higher protein content of VEGF-A and VEGFR-2 in neointima samples compared to the controls was also observed. No significant difference of VEGFR-1 content and VEGFR-1 mRNA expression was found in the studied material. Conclusion: These results indicate a possible involvement of the VEGF-A and VEGFR-2 system in the pathologic process of human neointima formation after vascular interventions.

(c) 2016 S. Karger AG, Basel

\section{Introduction}

Mechanical injury of the vessel wall induced by vascular interventions initiates the natural process of wound healing. Unfortunately, this excessive repair process often culminates in neointima formation. Thrombogenic vessel wall components are exposed due to damage to the endothelium, resulting in blood platelet activation with subsequent mural thrombus formation and the induction of a local inflammatory response. Myocytes and activated blood platelets release a number of peptide growth factors, adhesion molecules and other cytokines. Finally, vascular smooth muscle cell (VSMC) proliferation and migration with subsequent extracellular matrix deposition are the 
critical factors in the development of intimal hyperplasia. The newly formed structure composed of cells and fibers may lead to artery restenosis, which is the reason for the recurrence of disease symptoms and may be an indication for a secondary vascular intervention [1-4].

The vascular endothelial growth factor (VEGF) family has been the subject of extensive research in vascular biology for decades. VEGF is the key factor of vascular network formation under both physiological and pathological conditions. It acts mainly on endothelial cells as well as inflammatory cells and VSMC. VEGF is reported to induce cell proliferation and migration, and enhance vascular permeability. Moreover, it stimulates cells to increased extracellular matrix metabolism [5-7].

Since intimal hyperplasia relates to the alteration of endothelial function, inflammatory responses, and the migration and proliferation of smooth muscle cells, it can be assumed that VEGF may be involved in this process. However, the role of VEGF in neointima development remains controversial. Results of previous research vary depending on the applied research models. Moreover, animal models do not accurately reflect the human process of neointima formation [8-13]. Therefore, in our study we assessed the expression of VEGF-A and its receptors VEGFR-1 (flt-1) and VEGFR-2 (KDR) in human neointima formed within vascular anastomoses.

\section{Material and Methods}

The investigation protocol was approved by the Committee for Ethics and Supervision on Human and Animal Research of the Medical University of Białystok. All of the patients signed informed consent to being included in the study.

\section{Tissue Material}

The studied material comprised neointima specimens collected during secondary surgical vascular interventions. These were harvested from 12 patients (age range 50-60 years) with chronic limb ischemia who developed vascular graft occlusion at 16-18 months after the initial surgical treatment. At primary intervention all patients were stage 3 according to the Rutherford classification and presented type D aortoiliac lesions according the TASC II classification. The following surgical procedures were performed: aortobifemoral bypass in 3 patient, aortofemoral bypass in 4 patients and iliofemoral bypass in 5 patients. Outflow in all patients was preserved to deep femoral arteries. In the postoperative follow-up standard therapy was administered with $75 \mathrm{mg}$ of ASA daily and $20 \mathrm{mg}$ of simvastatin daily. All subjects stopped statins therapy for up to 6 months after the primary procedure. The patients who qualified for secondary interventions were at stage 4 according to the Rutherford classification. During surgical treatment vascular anastomosis was incised and graft thrombectomy was performed. After thrombus removal the glossy white tissue layer covering the inner anastomosis surface was carefully dissected and collected. Distal anastomosis was reconstructed with patch repair of the deep femoral artery in 7 patients and femoropopliteal bypass in 5 patients. The control material consisted of segments of common femoral arteries without visible macroscopic lesions collected from 12 age-matched organ donors. All collected samples were washed with a $0.9 \% \mathrm{NaCl}$ solution, weighed, aliquoted and stored at $-70^{\circ} \mathrm{C}$. There was no difference in the history of hypertension and diabetes mellitus, as well as pharmacotherapy with ACE and $\beta$-blockers between the studied groups. The operations were carried out in the Department of Vascular Surgery and Transplantation at the Medical University of Białystok.

\section{Content Evaluation of VEGF-A, VEGFR-1 and VEGFR-2}

The harvested tissue samples were cut into pieces, suspended in $0.05 \mathrm{M}$ Tris- $\mathrm{HCl}$ buffer $(\mathrm{pH}=7.6)$ in a $1: 3(\mathrm{w} / \mathrm{v})$ ratio, homogenized with a knife homogenizer $\left(25,000 \mathrm{rpm}\right.$ for $45 \mathrm{~s}$ at $\left.4^{\circ} \mathrm{C}\right)$ and then sonicated $\left(20 \mathrm{kHz}, 4 \times 15 \mathrm{~s}\right.$ at $\left.4^{\circ} \mathrm{C}\right)$. After centrifugation $\left(10,000 \mathrm{~g}\right.$ for $15 \mathrm{~min}$ at $\left.4^{\circ} \mathrm{C}\right)$ the protein content was determined according to the Bradford method in the obtained supernatants [14]. Contents of VEGF-A, VEGFR-1 and VEGFR-2 were assessed according to the ELISA method with the following commercially available kits: Quantikine Human VEGF Immunoassay (catalog No. DVE00; R\&D Systems Inc., Minneapolis, Minn., USA), Quantikine Human Soluble VEGF R1/Flt-1 Immunoassay (catalog No. DVR100B; R\&D Systems Inc.) and Quantikine Human Soluble VEGF R2/KDR Immunoassay (catalog No. DVR200; R\&D Systems Inc.). Measurements were carried out according to the manual provided by the manufacturer. The results are expressed per gram of tissue.

\section{Evaluation of VEGF-A, VEGFR-1 and VEGFR-2 mRNA}

Expression

A total of $50 \mathrm{mg}$ of harvested tissue was pulverized after immersion in liquid nitrogen. RNA was isolated with AxyPrep Multisource Total RNA Miniprep Kit (catalog No. AP-MN-MS-RNA-50; Axygen Bioscience, Union City, Calif., USA). The total RNA content was determined by measuring the absorbance at $260 \mathrm{~nm}$ in a spectrophotometer. The quality of isolated RNA was checked with a UV transilluminator after staining with ethidium bromide.

A total of $1 \mu \mathrm{g}$ of RNA was reverse-transcribed with the use of RevertAid $^{\mathrm{TM}}$ First Strand cDNA Synthesis Kit (catalog No. K1622; Fermentas, Vilnius, Lithuania) and oligo $(\mathrm{dT})_{18}$ primers. The cDNA was then amplified using polymerase chain reaction (PCR) carried out under standard conditions $[15,16]$. The primers used for human VEGF-A (sense $5^{\prime}$-TCTTGGGTGCATTGGAGCCTC- $3^{\prime}$, antisense $5^{\prime}$-AGCTCATCTCTCCTATGTGC-3') were designed to detect all isoforms of VEGF-A, yielding a product of 349 bp. Human VEGFR-1 primers (sense 5'-ATGGCTCCCGAATCTATCTTTGAC-3', antisense 5'-GCCCCGACTCCTTACTTTTACTGG- $3^{\prime}$ ) and VEGFR-2 primers (sense $5^{\prime}$-CTGGCGGCACGAAATATCCTCTTA-3', antisense 5'-GGGCACCATTCCACCAAAAGAT-3') amplified fragments of 655 and $777 \mathrm{bp}$, respectively. The primers used for VEGFR recognize the transmembrane full-length forms of receptors. Glyceraldehyde phosphate dehydrogenase (GAPDH) primers (sense $5^{\prime}$-AAATTGAGCCCGCAGCCTCCC-3', antisense 5'-GGTGACCAGGCGCCCAATACG- $3^{\prime}$ ) yielded a fragment of $159 \mathrm{bp}$.

Aliquots of $10 \mu \mathrm{l}$ of each amplification reaction were analyzed by electrophoresis in $2 \%$ agarose gel in the presence of $0.5 \mu \mathrm{g} / \mathrm{ml}$
48
Pathobiology 2016;83:47-52 DOI: $10.1159 / 000442885$
Bruczko/Wolańska/Małkowski/

Sobolewski/Kowalewski 
Fig. 1. The agarose gel electrophoresis of RT-PCR products of pooled homogenates from 12 samples of normal aorta and neointima. a $1 \mu \mathrm{g}$ of RNA was reverse transcribed with the use of oligo $(\mathrm{dT})_{18}$ primers and CDNA amplification was performed with VEGF-A, VEGFR-1, VEGFR-2 and GAPDH human primers. b The optical density of VEGF-A, VEGFR-1 and VEGFR-2 bands was normalized to its corresponding GAPDH band. The gene expression ratios in normal aorta were normalized to $100 \%$, and those in neointima were expressed relatively to normal aorta. Mean values \pm SD are presented $(n=12)$. * $\mathrm{p}<0.05$, normal aorta versus neointima.

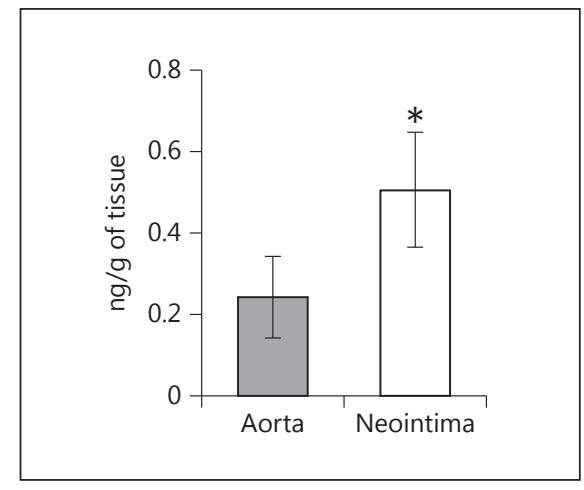

Fig. 2. The content of VEGF-A in normal aortic wall and neointima expressed as nanogram per gram of tissue. Mean values $\pm S D$ are presented $(n=12) .{ }^{*} p<0.05$, normal aorta versus neointima.

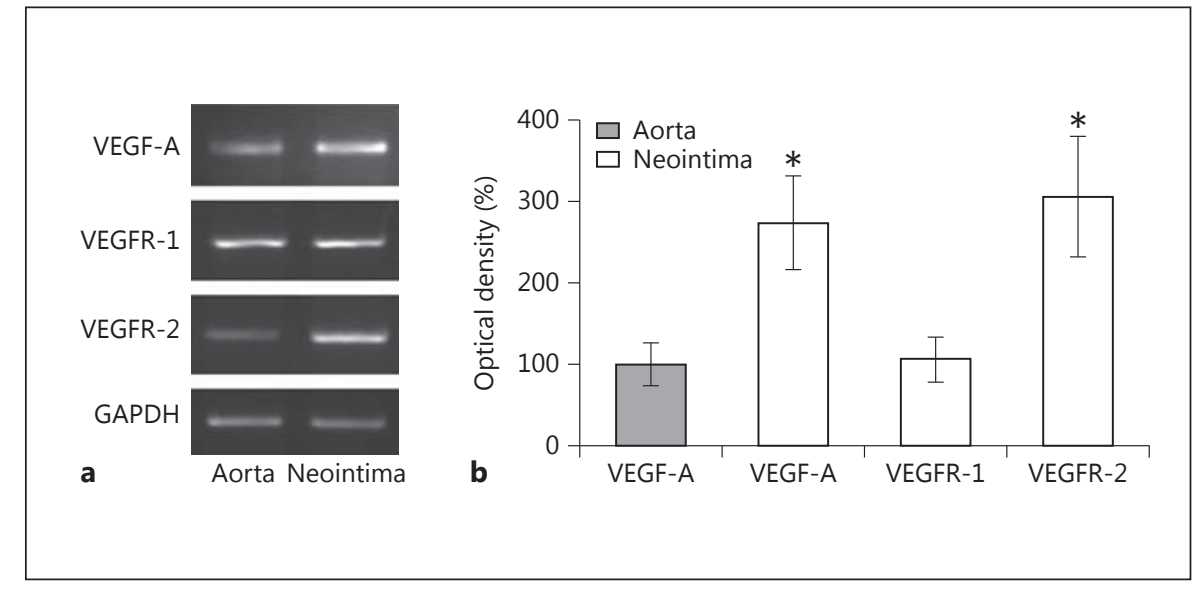

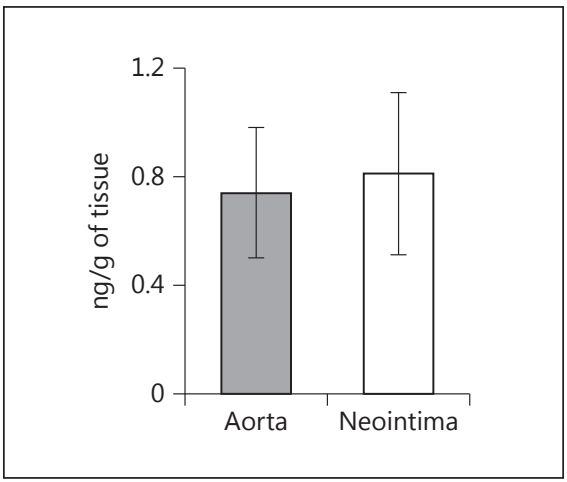

Fig. 3. The content of VEGFR-1 in normal aortic wall and neointima expressed as nanogram per gram of tissue. Mean values \pm SD are presented $(n=12)$.



Fig. 4. The content of VEGFR-2 in normal aortic wall and neointima expressed as nanogram per gram of tissue. Mean values $\pm \mathrm{SD}$ are presented $(\mathrm{n}=12) .{ }^{*} \mathrm{p}<0.05$, normal aorta versus neointima. of ethidium bromide. DNA was visualized under UV light. Contamination was routinely checked by an RT-PCR assay of RNA template-free samples (water control). The RT-PCR reaction products that were separated by agarose gel electrophoresis were photographed, scanned and analyzed using QuantityOne software (Bio-Rad, Hercules, Calif., USA). The optical density of the VEGFA, VEGFR-1 and VEGFR-2 bands was normalized to the corresponding GAPDH band. The gene expression ratios were normalized to $100 \%$ in normal aorta, whereas in neointima they were expressed relative to normal vessels.

\section{Statistical Analysis}

Statistical analysis of the obtained results was carried out by one-way analysis of variance followed by Tukey's test. The normal distribution of the obtained results was confirmed by a Kolmogorov-Smirnov one-sample test of normality, as well as the descriptive exploration and analysis of skewness. For all tests, a $\mathrm{p}$ value $<0.05$ was considered statistically significant. Mean values \pm standard deviations (SD) are presented.

VEGF and Neointima

\section{Results}

The expression of VEGF-A, VEGFR-1 and VEGFR-2 mRNA was demonstrated both in normal arteries and neointima (fig. 1a). The densitometric analysis is presented in figure 1b. A significantly increased ( $\mathrm{p}<0.05) \mathrm{VEGF}$ A mRNA expression was found in neointima (273.32\%) when compared with normal arteries (100\%). VEGFR-2 mRNA expression was significantly increased in neointima in comparison to control samples (306.2 vs. 100\%; $\mathrm{p}<0.05)$. However, no difference $(\mathrm{p}>0.05)$ in VEGFR-1 mRNA expression was found between the neointima and the control samples.

Total VEGF-A content in the normal artery wall and neointima is shown in figure 2 . It was significantly ( $\mathrm{p}<$ $0.05)$ increased in the neointima $(0.50 \pm 0.14 \mathrm{ng} / \mathrm{g}$ of tis- 
sue) when compared with the normal arteries $(0.24 \pm 0.10$ $\mathrm{ng} / \mathrm{g}$ of tissue).

The content of VEGFR-1 in the analyzed tissues is presented in figure 3 . There were no significant differences $(\mathrm{p}>0.05)$ in the VEGFR-1 content in neointima ( $0.81 \pm$ $0.30 \mathrm{ng} / \mathrm{g}$ of tissue) in comparison with the normal artery wall $(0.74 \pm 0.24 \mathrm{ng} / \mathrm{g}$ of tissue).

The content of VEGFR-2 in the analyzed tissues is presented in figure 4. A higher content of VEGFR-2 was shown in neointima $(8.24 \pm 1.98 \mathrm{ng} / \mathrm{g}$ of tissue) compared to control samples $(3.95 \pm 1.53 \mathrm{ng} / \mathrm{g}$ of tissue). These differences were statistically significant $(\mathrm{p}<0.05)$.

\section{Discussion}

Mechanical damage of endothelium induces many cellular and molecular mechanisms within the vascular lumen and wall. Vascular homeostasis disturbances are followed by smooth muscle cell proliferation and migration. These proliferative and migratory events may extend beyond the normal healing process and result in neointimal hyperplasia [1-4].

The potential role of VEGF in cardiovascular diseases, including the atherosclerotic process, has been evaluated in numerous studies. Most of them reported increased VEGF expression in response to vascular injury $[17,18]$.

The present study shows VEGF-A presence in human neointima collected from patients who developed vascular graft thrombosis due to distal anastomosis stenosis or occlusion. An increase in VEGF-A mRNA expression has been observed in neointima compared to a normal artery. The difference was also demonstrated at the protein level. These results suggest a possible role of VEGF in the development and remodeling of neointima in humans.

Based on numerous animal studies, two opposite mechanisms of VEGF activity in the damaged arterial wall have been shown. On the one hand, VEGF accelerates endothelium regeneration due to its ability to promote endothelial cell migration and proliferation $[8,9]$. A significant increase in VEGF expression has been shown $48 \mathrm{~h}$ after the artery injury [19]. Moreover, endothelium regeneration stimulated by VEGF resulted in a significant decrease in neointima formation [20-22]. That was confirmed by therapeutic application of VEGF gene transfer to reduce neointimal hyperplasia induced by endothelial denudation [23-25].

On the other hand, many reports suggest that VEGF supports the process of neointima formation [10-12]. This discrepancy may result from different experimental procedures. The extent of vascular injury may also be of some importance. In a relatively moderate injury, the predominant target of VEGF seems to be endothelial cells, and VEGF might preferentially act on these cells to enhance reendothelialization and consequently inhibit neointima formation. In a severe injury, however, medial smooth muscle cells are disclosed and remain prone to VEGF influence.

Furthermore, exogenous VEGF stimulates neointima formation under experimental conditions. It should be emphasized that the amount of endogenous VEGF is increased in hypercholesterolemia, which is a risk factor of atherosclerosis. The reason for this is the low-density lipoprotein fraction, which enhances VEGF synthesis by VSMC and macrophages [26, 27]. It cannot be excluded that VEGF can stimulate intimal hyperplasia even after complete reendothelialization.

In animal models, the increased expression of VEGF was present a few weeks after stenting, while reendothelialization was complete within 2 weeks [10]. Our results also demonstrated an increased expression and content of VEGF in mature neointima, taken at least 6 months after the initial surgery of bypass grafting. It should be noted that the time course of reendothelialization and neointimal growth varies between different animal species and humans. In animal models, peak neointimal growth is observed at 28 days following a surgical intervention, whereas in humans it is identified after between 6 and 12 months [1]. Thus, it can be assumed from our findings that VEGF participates not only in the neointima development, but also in the further stages of its remodeling.

The migration of smooth muscle cells towards the vessel lumen is the key step in neointima formation. These cells then proliferate and synthesize a number of cytokines and extracellular matrix components, which culminate in neointimal hyperplasia. It has also been observed that in vitro VSMC migration increases in response to VEGF $[28,29]$.

The consequences of VEGF gene transfer may be dependent on the applied method and do not always manifest in neointimal attenuation. It is known that the introduced VEGF gene may increase VSMC migration and proliferation accompanied by a rise in the synthesis and secretion of extracellular matrix metalloproteinases (MMP-2 and MMP-9) [12]. Wang and Keiser [30] have shown that VEGF treatment upregulates the expression of MMPs in VSMC through the activation of the VEGFR-1 receptor (flt-1). Thus, VSMC-derived MMPs could digest the vascular basement membrane and there-
Bruczko/Wolańska/Małkowski/ Sobolewski/Kowalewski 
by facilitate the motility of these cells. Previous studies have confirmed the expression of VEGFR-1 and VEGFR-2 in VSMC $[28,29]$. Our study has shown no differences in the expression of VEGFR-1 in neointima and normal artery, with its content remaining at a similar level in both. In contrast, we observed a significantly higher expression and concentration of VEGFR-2 in neointima compared to the control samples. Therefore, one may speculate that the receptor mainly involved in the pathogenesis of neointima remodeling in humans is VEGFR-2. This is confirmed by previous studies showing that VEGFR-2 activation induces cell migration, while VEGFR-1 activation does not provide such a response $[7,28,29]$. This can be explained by the fact that the activation of solely VEGFR-2 upregulates the MAP kinase expression [31], which may result in mitogenic activity of cells. Other studies have found that proliferating and migrating endothelial cells express a high level of VEGFR-1 (flt-1). However, VEGF infusion failed to induce a proliferative response in these cells. At sites of flt-1 expression, only increased vascular permeability was seen [32].

The proliferative and migratory state of VSMCs is stimulated by inflammation directly after implantation of the vascular prosthesis. Activated VSMCs promote monocyte migration to the site of vascular injury which in turn sustains VSMC proliferation by chemokine production. Thus, the role of monocytes and macrophages in an inflammatory cascade creates a milieu for neointima formation. It has been demonstrated that monocyte chemotaxis in response to VEGF is mediated by the flt- 1 receptor [33]. However, an absence of acute and chronic inflammation was reported in neointimal specimens at 6 months [34]. Consequently, we cannot exclude a different VEGFR-1 expression in the early steps of neointima formation, although we did not demonstrate any significant difference in VEGFR-1 in specimens obtained at 6-18 months after the primary operation.
VEGF-induced monocyte accumulation at the site of injury via flt- 1 has long been considered a prerequisite in neointimal formation [13]. The studies demonstrating that VSMC stimulation by VEGF via VEGFR-2 results in the expression of monocyte chemoattractant protein-1 (MCP-1) have provided crucial information to this process of understanding $[35,36]$. Secreted MCP- 1 may then induce inflammatory cell accumulation. VEGFR-2 blockage resulted in the suppression of neointima formation, following the reduced MCP-1 expression in the VSMC and monocyte chemotaxis inhibition. This also resulted in impaired VSMC proliferation and blockage of perivascular neovascularization. Thus, the entire process of neointimal formation regulated by VEGF appears to be independent of VEGFR-1 signaling. Some scientific reports indicate that most angiogenic signals induced by VEGFA also require activation of VEGFR-2 [31,37]. In research conducted by Koga et al. [35], it was observed that blockage of VEGFR-2 inhibits neovascularization and, consequently, limits neointimal hyperplasia. Thus, elevated levels of VEGF-A and its receptor VEGFR-2 may also be an important factor for microvessel formation in neointima. Immunohistochemical analysis of human restenosis at different time points after stenting revealed that vessel wall thickening is accompanied, inter alia, by VEGF-A expression and extensive neovascularization [38]. Similar observations were also made in atherosclerosis. The more advanced the atherosclerotic lesion is, the more developed the intimal blood microvessel network becomes, and the greater the number of VEGF-positive cells are found $[39,40]$. It can be assumed that the newly formed microvessels could support the growth of pathological tissue, improving the delivery of proinflammatory factors, growth factors and nutrients. It has also been shown that the density of blood vessels within the neointima affects its size and the congestion of inflammatory cells [41, 42].

\section{References}

1 Chaabane C, Otsuka F, Virmani R, BochatonPiallat ML: Biological responses in stented arteries. Cardiovasc Res 2013;99:353-363.

2 Costa MA, Simon DI: Molecular basis of restenosis and drug-eluting stents. Circulation 2005;111:2257-2273.

3 Majesky MW: Neointima formation after acute vascular injury: role of counteradhesive extracellular matrix proteins. Tex Heart Inst J 1994;21:78-85.
4 Goel SA, Guo LW, Liu B, Kent KC: Mechanisms of post-intervention arterial remodelling. Cardiovasc Res 2012;96:363-371.

5 Yla-Herttuala S, Rissanen TT, Vajanto I, Hartikainen J: Vascular endothelial growth factors: biology and current status of clinical applications in cardiovascular medicine. J Am Coll Cardiol 2007;49:1015-1026.

6 Shibuya M: Vascular endothelial growth factor and its receptor system: physiological functions in angiogenesis and pathological roles in various diseases. J Biochem 2013;153:13-19.
7 Neufeld G, Cohen T, Gengrinovitch S, Poltorak Z: Vascular endothelial growth factor (VEGF) and its receptors. FASEB J 1999;13: 9-22.

8 Callow AD, Choi ET, Trachtenberg JD, Stevens SL, Connolly DT, Rodi C, Ryan US: Vascular permeability factor accelerates endothelial regrowth following balloon angioplasty. Growth Factors 1994;10:223-228. 
9 Burke PA, Lehmann-Bruinsma K, Powell JS: Vascular endothelial growth factor causes endothelial proliferation after vascular injury. Biochem Biophys Res Commun 1995;207: 348-354.

10 Shibata M, Suzuki H, Nakatani M, Koba S, Geshi E, Katagiri T, Takeyama Y: The involvement of vascular endothelial growth factor and flt- 1 in the process of neointimal proliferation in pig coronary arteries following stent implantation. Histochem Cell Biol 2001; 116:471-481.

11 Ohtani K, Egashira K, Hiasa K, Zhao Q, Kitamoto $\mathrm{S}$, Ishibashi $\mathrm{M}$, Usui $\mathrm{M}$, Inoue $\mathrm{S}$, Yonemitsu Y, Sueishi K, Sata M, Shibuya M, Sunagawa $\mathrm{K}$ : Blockade of vascular endothelial growth factor suppresses experimental restenosis after intraluminal injury by inhibiting recruitment of monocyte lineage cells. Circulation 2004;110:2444-2452.

12 Bhardwaj S, Roy H, Heikura T, Ylä-Herttuala S: VEGF-A, VEGF-D and VEGF-D ${ }^{\Delta \mathrm{N} \Delta \mathrm{C}}$ induced intimal hyperplasia in carotid arteries. Eur J Clin Invest 2005;35:669-676.

13 Zhao Q, Egashira K, Hiasa K, Ishibashi M, Inoue S, Ohtani K, Tan C, Shibuya M, Takeshita A, Sunagawa K: Essential role of vascular endothelial growth factor and flt- 1 signals in neointimal formation after periadventitial injury. Arterioscler Thromb Vasc Biol 2004;24: 2284-2289.

14 Bradford MM: A rapid and sensitive method for the quantitation of microgram quantities of protein utilizing the principle of proteindye binding. Anal Biochem 1976;72:248-254.

15 Kowalewski R, Malkowski A, Sobolewski K, Gacko M: Evaluation of aFGF/bFGF and FGF signaling pathway in the wall of varicose veins. J Surg Res 2009;155:165-172.

16 Kowalewski R, Malkowski A, Sobolewski K, Gacko M: Evaluation of transforming growth factor-beta signaling pathway in the wall of normal and varicose veins. Pathobiology 2010;77:1-6.

17 Ruef J, Hu ZY, Yin LY, Wu Y, Hanson SR, Kelly AB, Harker LA, Rao GN, Runge MS, Patterson C: Induction of vascular endothelial growth factor in balloon-injured baboon arteries: a novel role for reactive oxygen species in atherosclerosis. Circ Res 1997;81:2433.

18 Hausner EA, Orsini JA, Foster LL, Modzelewski TC, Merrill JJ, Perkowski SZ, Slee A: Vascular endothelial growth factor in porcine coronary arteries following balloon angioplasty. J Invest Surg 1999;12:15-23.

19 Hamdan AD, Aiello LP, Misare BD, Contreras MA, King GL, LoGerfo FW, Quist WC: Vascular endothelial growth factor expression in canine peripheral vein bypass grafts. J Vasc Surg 1997;26:79-86.

20 Hutter R, Carrick FE, Valdiviezo C, Wolinsky C, Rudge JS, Wiegand SJ, Fuster V, Badimon JJ, Sauter BV: Vascular endothelial growth factor regulates reendothelialization and neointima formation in a mouse model of arterial injury. Circulation 2004;110:2430-2435.
21 Asahara T, Bauters C, Pastore C, Kearney M, Rossow S, Bunting S, Ferrara N, Symes JF, Isner JM: Local delivery of vascular endothelial growth factor accelerates reendothelialization and attenuates intimal hyperplasia in ballooninjured rat carotid artery. Circulation 1995; 91:2793-2801.

22 Tang C, Wang G, Wu X, Li Z, Shen Y, Lee JC, Yu Q: The impact of vascular endothelial growth factor-transfected human endothelial cells on endothelialization and restenosis of stainless steel stents. J Vasc Surg 2011;53:461471.

23 Asahara T, Chen D, Tsurumi Y, Kearney M, Rossow S, Passeri J, Symes JF, Isner JM: Accelerated restitution of endothelial integrity and endothelium-dependent function after phVEGF165 gene transfer. Circulation 1996; 94:3291-3302.

24 van Belle E, Maillard L, Tio FO, Isner JM: Accelerated endothelialization by local delivery of recombinant human vascular endothelial growth factor reduces in-stent intimal formation. Biochem Biophys Res Commun 1997; 235:311-316.

25 Hiltunen MO, Laitinen M, Turunen MP, Jeltsch M, Hartikainen J, Rissanen TT, Laukkanen J, Niemi M, Kossila M, Häkkinen TP, Kivelä A, Enholm B, Mansukoski H, Turunen AM, Alitalo K, Ylä-Herttuala S: Intravascular adenovirus-mediated VEGF-C gene transfer reduces neointima formation in balloon-denuded rabbit aorta. Circulation 2000;102: 2262-2268.

26 Dulak J, Jozkowicz A, Dichtl W, Alber H, Schwarzacher SP, Pachinger O, Weidinger F: Vascular endothelial growth factor synthesis in vascular smooth muscle cells is enhanced by 7-ketocholesterol and lysophosphatidylcholine independently of their effect on nitric oxide generation. Atherosclerosis 2001;159: 325-332.

27 Inoue M, Itoh H, Tanaka T, Chun TH, Doi K, Fukunaga Y, Sawada N, Yamshita J, Masatsugu K, Saito T, Sakaguchi S, Sone M, Yamahara Ki, Yurugi T, Nakao K: Oxidized LDL regulates vascular endothelial growth factor expression in human macrophages and endothelial cells through activation of peroxisome proliferator-activated receptor-gamma. Arterioscler Thromb Vasc Biol 2001;21: 560-566.

28 Grosskreutz CL, Anand-Apte B, Dupláa C, Quinn TP, Terman BI, Zetter B, D'Amore PA: Vascular endothelial growth factor-induced migration of vascular smooth muscle cells in vitro. Microvasc Res 1999;58:128-136.

29 Ishida A, Murray J, Saito Y, Kanthou C, Benzakour O, Shibuya M, Wijelath ES: Expression of vascular endothelial growth factor receptors in smooth muscle cells. J Cell Physiol 2001;188:359-368.

30 Wang H, Keiser JA: Vascular endothelial growth factor upregulates the expression of matrix metalloproteinases in vascular smooth muscle cells: role of flt-1. Circ Res 1998;83: 832-840.
31 Kroll J, Waltenberger J: The vascular endothelial growth factor receptor KDR activates multiple signal transduction pathways in porcine aortic endothelial cells. J Biol Chem 1997; 272:32521-32527.

32 Lindner V, Reidy MA: Expression of VEGF receptors in arteries after endothelial injury and lack of increased endothelial regrowth in response to VEGF. Arterioscler Thromb Vasc Biol 1996; 16:1399-1405.

33 Barleon B, Sozzani S, Zhou D, Weich HA, Mantovani A, Marmé D: Migration of human monocytes in response to vascular endothelial growth factor (VEGF) is mediated via the VEGF receptor flt-1. Blood 1996;87:3336-3343.

34 Busch A, Hartmann E, Wagner N, Ergün S, Kickuth R, Kellersmann R, Lorenz U: Neointimal hyperplasiain allogeneic and autologous venous grafts is not different in nature. Histochem Cell Biol 2015;144:59-66.

35 Koga J, Matoba T, Egashira K, Kubo M, Miyagawa M, Iwata E, Sueishi K, Shibuya M, Sunagawa K: Soluble flt-1 gene transfer ameliorates neointima formation after wire injury in flt-1 tyrosine kinase-deficient mice. Arterioscler Thromb Vasc Biol 2009;29:458-464.

36 Bhardwaj S, Roy H, Babu M, Shibuya M, YlaHerttuala S: Adventitial gene transfer of VEGFR-2 specific VEGF-E chimera induces MCP-1 expression in vascular smooth muscle cells and enhances neointimal formation. Atherosclerosis 2011;219:84-91.

37 Zachary I: Signal transduction in angiogenesis. EXS 2005;94:267-300.

38 Brasen JH, Kivela A, Roser K, Rissanen TT, Niemi M, Luft FC, Donath K, Ylä-Herttuala $S$ : Angiogenesis, vascular endothelial growth factor and platelet-derived growth factor-BB expression, iron deposition, and oxidationspecific epitopes in stented human coronary arteries. Arterioscler Thromb Vasc Biol 2001; 21:1720-1726.

39 Chen YX, Nakashima Y, Tanaka K, Shiraishi S, Nakagawa K, Sueishi K: Immunohistochemical expression of vascular endothelial growth factor/vascular permeability factor in atherosclerotic intimas of human coronary arteries. Arterioscler Thromb Vasc Biol 1999; 19:131-139.

40 Inoue $\mathrm{M}$, Itoh $\mathrm{H}$, Ueda $\mathrm{M}$, Naruko $\mathrm{T}$, Kojima A, Komatsu R, Doi K, Ogawa Y, Tamura N, Takaya K, Igaki T, Yamashita J, Chun TH, Masatsugu K, Becker AE, Nakao K: Vascular endothelial growth factor (VEGF) expression in human coronary atherosclerotic lesions: possible pathophysiological significance of VEGF in progression of atherosclerosis. Circulation 1998;98:2108-2116.

41 Farb A, Weber DK, Kolodgie FD, Burke AP, Virmani R: Morphological predictors of restenosis after coronary stenting in humans. Circulation 2002;105:2974-2980.

42 Zhang M, Cresswell N, Tavora F, Mont E, Zhao Z, Burke A: In-stent restenosis is associated with neointimal angiogenesis and macrophage infiltrates. Pathol Res Pract 2014;210: 1026-1030. 